\title{
LAS FUENTES DE LA ASTROLOGÍA DURANTE EL RENACIMIENTO: ALGUNAS CONSIDERACIONES*
}

\author{
Cristóbal Macías Villalobos - Delia Macías Fuentes \\ Universidad de Málaga \\ cmacias@uma.es - deliamacias@uma.es
}

\begin{abstract}
RESUMEN
Durante el Renacimiento, la recuperación de los principales textos de la astrología antigua, en particular de Tolomeo, posibilitó un movimiento de reforma de la pseudociencia que pretendía eliminar todos los elementos de origen medieval, vinculados con la astrología árabe, algo que no se logró por las limitaciones de la doctrina tolemaica. En este trabajo analizaremos algunas de las fuentes principales de que se nutrió la práctica astrológica durante los siglos XV y XVI, principalmente, y de qué manera contribuyeron a modelar el arte astrológico de entonces.
\end{abstract}

PALABRAS ClaVE: Renacimiento, astrología, Tolomeo, Abu Ma’shar, hermetismo.

\section{SOME CONSIDERATIONS ABOUT THE SOURCES OF ASTROLOGY \\ AT THE TIME OF THE RENAISSANCE}

\section{ABSTRACT}

During the Renaissance period, the recovery of the main texts of ancient astrology, particularly Ptolemy, made possible a movement to reform pseudoscience that sought to eliminate all elements of medieval origin, linked to Arabic astrology. However this target was not achieved, motivated by limitations in Ptolemaic doctrines. In this paper we will analyze some of the main sources from which astrological practice was nurtured mainly during the $15^{\text {th }}$ and $16^{\text {th }}$ centuries, and in what way they contributed to shaping the astrological art of that time.

KeYwords: Renaissance, astrology, Ptolemy, Abu Ma'shar, Hermeticism.

En la historia de la astrología occidental, los siglos XV y XVI son uno de los periodos más interesantes, pero a la vez más complejos. De entrada, supuso la época de su máximo apogeo (Hübner, 2014: 17), al menos desde la restauración de la astrología en el siglo XII, no solo en lo que se refiere a la evolución de las doctrinas y técnicas, sino sobre todo por su presencia en prácticamente todos los órdenes de la vida cotidiana.

En lo referente a la literatura astrológica y sus contenidos, se pueden distinguir dos periodos perfectamente diferenciados: el primero, hasta finales del siglo XV, de continuidad respecto a la astrología medieval, basada sobre todo en las fuentes 
árabes y hebreas, introducidas en Occidente gracias a traducciones de las mismas al latín, al cual se adscriben los astrólogos más conservadores; y el segundo, que se inicia a finales del siglo XV, y sobre todo a comienzos del XVI, en el que, coincidiendo con la recuperación de la obra original de Tolomeo, sobre todo, el Tetrabiblos y el Centiloquium, un tratado atribuido entonces erróneamente al autor alejandrino -y de otros muchos autores clásicos-, surge una fuerte corriente de autores reformistas de la astrología, que pretendían liberarla de las nugae Arabum, es decir, de todos aquellos contenidos doctrinales y técnicas que no estuvieran atestiguados en las fuentes antiguas, fundamentalmente helenísticas (Faracovi, 2014: 87), algo que, como veremos, no se logró.

Pero junto a las fuentes antiguas y medievales, en el Renacimiento se publicaron algunas obras que ejercieron una influencia muy notable ya en los astrólogos de entonces, por lo que en nuestro trabajo las vamos a considerar también fuentes del arte astrológico renacentista. Nos referimos, en concreto, al Disputationes adversus astrologiam divinatricem, de Pico della Mirandola, publicado póstumamente en 1496, que pasa por ser el principal alegato contra la pseudociencia del momento y que llevó a una parte de los astrólogos a replantearse los fundamentos de su ciencia; al De vita de Marsilio Ficino, publicada en 1489, sobre todo su libro tercero, De vita coelitus comparanda, que influyó notablemente en la difusión de la magia astral talismánica y en los tratados de medicina astral que se compusieron entonces, y al De revolutionibus orbium coelestium, la obra más importante de Nicolás Copérnico, publicada el año de su muerte, 1543, donde exponía su teoría heliocéntrica, con la que pretendía resolver los errores que contenía la teoría tolemaica del movimiento de los planetas.

Respecto a Tolomeo, cuya recuperación constituye sin duda la principal aportación del Renacimiento a la historia de la astrología ${ }^{1}$, su Tetrabiblos o Quadripartitum, junto con el Centiloquium, era conocido en los siglos finales del Medievo gracias a las traducciones latinas del árabe, obra de Platón de Tivoli, Juan de Sevilla, Hugo de Santalla y Herman de Carintia. Con la llegada de la imprenta, todas estas versiones fueron publicadas por primera vez en Venecia en 1493, seguidas por otras versiones en la propia Venecia en 1519 y en Basilea en 1533. Incluso, todavía en 1548, la versión del Liber Quadripartitus de Juan de Sevilla fue editada en solitario en Nuremberg con el título de Epitome totius astrologiae (Faracovi, 2014: 89-90, n. 4). Esto

* Este trabajo se encuadra en el «Proyecto I+D de Generación de Conocimiento» CORPVS DE la literatura latina Del ReNACIMIENTO ESPAÑOl. IX Referencia PGC2018-094604-B-C31 (MCIU/AEI/FEDER, UE). Dedicamos este trabajo al Dr. don Ángel Martínez Fernández, Catedrático de Filología Griega de la Universidad de La Laguna, por habernos honrado con su amistad desde hace ya muchos años y en reconocimiento a su gran valía académica y científica.

${ }^{1}$ Su obra astronómica, el Almagesto, que fue traducida al menos dos veces al latín, en 1150 por Herman de Carintia y en torno a 1175 por Gerardo de Cremona, formaba parte de la enseñanza más tradicional, junto al autor árabe Alfragnano y al inglés Sacrobosco, cuyo Tractatus de Sphaera gozó de gran fama hasta el Renacimiento. Por eso Melanchton, cuando conoció la Narratio prima de Rheticus, donde se resumían los puntos principales de la teoría heliocéntrica de Copérnico, se opuso a que aquel enseñara las nuevas ideas en sus clases de matemáticas en Wittenberg (Vernet, 2000: 43). 
revela que las versiones latinas medievales del autor alejandrino siguieron disfrutando de renombre y consideración hasta bien entrado el periodo renacentista.

La recuperación de Tolomeo por los humanistas se llevó a cabo mediante la realización de nuevas ediciones, traducciones y comentarios, y estos empezaron paradójicamente por una obra que, aunque atribuida entonces al autor alejandrino, no es realmente suya, el Centiloquium.

La primera traducción del Centiloquium en esta nueva etapa fue la de Jorge de Trebizonda, de mediados del XV, aunque fue publicada casi un siglo después, en 1540, en Roma por el astrólogo italiano Luca Gaurico, con el título Claudii Ptolemaei Alexandrini astronomorum principis centum sententiae, interprete Georgio Trapezunzio, junto con la Oratio de inventoribus, utilitate et laudibus astronomiae del propio Gaurico. La segunda cronológicamente fue la de Giovanni Pontano, con un comentario, impresa póstumamente en Nápoles en 1512, con el título de Pontani Commentationes super sententiis Ptolemaei (Faracovi, 2014: 92, n. 11).

Como es sabido, el Centiloquium, conocido también por el título griego de Karpos y el latino de Fructus, porque se suponía que abarcaba el fruto de las doctrinas tolemaicas, es una obra de origen incierto, en donde, en apenas cien aforismos o sentencias (de ahí el título latino), se pretenden resumir los contenidos fundamentales de la astrología tolemaica, si bien solo una parte de las sentencias son resumen de doctrinas del Tetrabiblos, siendo el resto de origen hermético y árabe. A pesar de ello y de la notable oscuridad de muchos de los aforismos, quizás por su carácter de resumen, tuvo una amplia difusión y fue traducida en el Medievo antes incluso que el propio Tetrabiblos, en concreto, ya en 1136.

Respecto a su origen, es posible que su primera versión fuera latina. En los primeros años del siglo $\mathrm{X}$, al-Dayah hizo una versión árabe y la atribuyó a Tolomeo, recurriendo así a la autoridad del autor griego para aumentar el prestigio de su propio trabajo, añadiéndole además un comentario. Tanto la versión árabe como el comentario fueron traducidos al latín por Juan de Sevilla, Platón de Tivoli y Hugo de Santalla. Los manuscritos griegos más antiguos datan del siglo XIV y, como demostró Franz Boll a finales del XIX, el griego de los mismos es muy posterior a la época de Tolomeo (Faracovi, 2014: 91-92). Finalmente, el humanista y astrólogo italiano Girolamo Cardano, en su comentario del Tetrabiblos, publicado en Basilea en 1554 bajo el título In Cl. Ptolemaei... Quadripartitae constructionis libros commentaria, demostró sin lugar a duda que el Centiloquium no era obra de Tolomeo, sino de alguien que no solo no había comprendido, sino que incluso había deformado sus doctrinas (Faracovi, 2014: 93).

Respecto al Tetrabiblos, en 1477-1491, Lorenzo Bonincontri compuso un Tractatus sobre el Tetrabiblos, que fue también comentado por Giorgio Valla, Preclarissimi viri Georgij Valle Commentationes. In Ptolemei quadripartitum [...] quaestiones [...] (Venecia, 1502); por Agostino Nifo, Ad Sylvium Pandonium Boviani episcopum Eutichi Augustini Niphi Philothei Suessani ad Apotelesmata Ptolemaei eruditiones (Nápoles, 1513)

${ }^{2}$ Cf. Bezza (2014: 82, n. 79). 
por Girolamo Cardano, Hieronymi Cardani [... ] in Cl. Ptolemaei Pelusiensis IIII de Astrorum Iudiciis, aut, ut vulgo vocant, Quadripartitae Constructionis, libros commentaria [...], Basilea, 1554, y Londres, 1555, considerado unánimemente como el mejor comentario de esta obra durante el Renacimiento; y posteriormente por Franciscus Iunctinus, De divinatione, quae fit per astra, diversum ac discrepans duorum catholicorum sacra Theologiae Doctorum: scilicet Francisci Iunctini ac Ioannis Lensaei [... (Colonia, 1580). Habrá que esperar hasta el año 1535 para encontrar la primera edición del texto griego del Tetrabiblos (que solía editarse a menudo junto con el Centiloquium) junto con la traducción directa del griego, en este caso de solo los dos primeros libros (y de dos capítulos del libro tercero), obra de Joachim Camerarius (Cl. Ptolemaei libri quattuor composito Syro fratri [... traductio in linguam latinam librorum Ptolemaei duum priorum [...] Joachimi Camerarii Pabergensis, aparecida en Nuremberg) ${ }^{3}$, que fue seguida por otra ya completa de Antonio Gogava, publicada en Lovaina en 1548, bajo el título Cl. Ptolemaei Pelusiensis mathematici operis quadripartitii in latinum sermonem traductio. Finalmente, del año 1553 es la edición del texto griego con traducción latina de Melanchton, con el título Claudii Ptolemaei de Praedictionibus astronomicis, cui titulum fecerunt Quadripartitum, graece et latine, libri IIII, Philippo Melanthone interprete. Ejusdem Fructus librorum suorum, sive Centum dicta, ex conversione Joviani Pontani [...], publicada en Basilea (cf. Hübner, 2014: 19-20, n. 16 a 20).

Junto con la obra de Tolomeo se editaron también entonces otros textos antiguos compuestos en su momento como paráfrasis o comentarios del autor alejandrino, a saber, el comentario griego de Proclo, editado también por Melanchton, con el título de Procli paraphrasis in quatuor Ptolemaei libros de siderum effectionibus (Basilea, 1554), que conoció una edición posterior, ya en el XVII (Leyden, 1635),

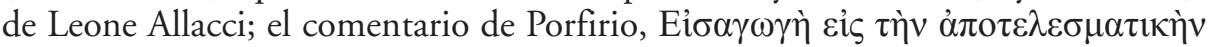

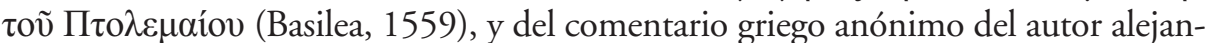

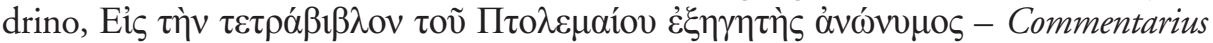
anonymus in Claudii Ptolemaei quadripartitum (Basilea, 1559), ambos de un discípulo de Melanchton, Hieronymus Wolf, que atribuyó erróneamente este último tratado al propio Proclo (cf. Hübner, 2014: 20, n. 21 a 23).

De entre todas las traducciones aparecidas entonces, una de las más apreciadas fue la de Gogava, pues con ella los autores del Renacimiento pudieron contar con una versión del texto tolemaico libre de barbarismos, que demostraba bien a las claras lo alejados que habían estado del verdadero arte los astrólogos del pasado, como destacaba Regnier Gemma Frisius en su introducción a la versión de Gogava (Bezza, 2014: 78).

Asimismo, al disponer del texto original del maestro alejandrino, los reformadores de la astrología, entre los cuales destacará el ya mencionado Girolamo Cardano, estaban en disposición de distinguir entre la verdadera y la falsa astrología, entendiendo

${ }^{3}$ Para el resto de los libros, Camerarius recurrió a la traducción latina del árabe, obra de Platón de Tivoli (cf. Bezza, 2014: 78). 
por esta última la astrología medieval, plagada de arabismos, de superstición y de prácticas adivinatorias. El objetivo de la astrología dejará de ser la adivinación, para centrarse en la predicción a partir de signos reales, justo como hacía el médico a partir de las venas y la orina del enfermo (Bezza, 2014: 79).

Y es que, en efecto, Tolomeo había tratado de buscar causas naturales en las que apoyar los pronósticos, para lo cual se había basado en la teoría aristotélica de las propiedades elementales de la materia (Feraboli, 2010: XVI). Al reconocer, a partir de la física aristotélica, que los cuerpos celestes podían ejercer ciertas influencias y causar efectos naturales importantes en los seres vivos, algo que se podía comprobar empíricamente, también se eliminaba cualquier tipo de magia en la que se presumía la acción de demonios o energías espirituales, por lo que solo quedaba espacio para la magia natural (Faracovi, 2014: 95).

Por su parte, Melanchton fue también otro reformador de la astrología, arte que aprendió en Tubinga de su maestro Johannes Stöffler. Conocía muy bien el Tetrabiblos, del que hizo lecturas públicas en la Universidad de Wittenberg entre 1535 y 1546. Su objetivo era elevar la astrología a la categoría de ciencia universal. Así mismo, la consideraba pars physicae, es decir, parte del estudio de la naturaleza. La astrología demostraría al hombre en qué consiste la voluntad divina y cómo funciona la providencia de Dios, entre otras cosas (Bezza, 2014: 79).

Por paradójico que parezca, Pico della Mirandola, uno de los principales exponentes del rechazo a la astrología durante el Renacimiento gracias a sus Disputationes adversus astrologiam divinatricem, publicado póstumamente en 1496 por su sobrino Gianfrancesco Pico della Mirandola, tenía en cierta estima al autor alejandrino, al que consideraba como el optimus malorum (Disputationes I, I, 70), cuya obra, tanto la escrita por él como la falsamente atribuida, conocía bien, incluyendo el Almagesto. De hecho, su estrategia polémica consistirá en enfrentar a Tolomeo con sus seguidores para poner de relieve las contradicciones y disonancias de la tradición astrológica, en la idea de que aquellos no comprendieron o distorsionaron sus doctrinas (Akopyan, 2017: 547-548).

Para ello se sirve de dos tipos de argumentos. Por un lado, trata de demostrar que Abu Ma’shar y otros se equivocan con frecuencia al interpretar los términos astrológicos de Tolomeo, por lo que los usan en un sentido completamente diferente. Asimismo, en el caso del Centiloquium, Pico pone de relieve los puntos que entran en contradicción con otros textos de Tolomeo. Para explicar estas contradicciones, Pico sostiene que los astrólogos que se sirven de esta obra no usaron el texto original, sino una traducción en la que las ideas de Tolomeo estaban distorsionadas. De hecho, afirma que comparando la traducción latina del Centiloquium con el texto original había detectado más de seiscientos errores (Disputationes, I, II, 154-6) (Akopyan, 2017: 549).

\footnotetext{
${ }^{4}$ Lo más probable es que Pico manejara la traducción de Pontano, antes que las numerosas traducciones medievales.
} 
Entre los puntos que Pico trata en sus Disputationes para destacar las inconsistencias de la pseudociencia, uno de los más importantes tiene que ver con los decanos y, de paso, con el uso que los astrólogos hacen de los signos zodiacales. En esencia, su crítica tiene que ver con la idea de que se trata de imágenes artificiales y ficticias, inventadas por los astrólogos, pero sin ninguna evidencia matemática o física: «He accuses Ptolemy and his less gifted followers of an unconvincing attempt to link the basic elements of the world with artificial and fictitious astrological images» (Akopyan, 2017: 557).

Respecto al sistema de los decanos, Pico pone de relieve las divergencias entre las distintas tradiciones astrológicas en cuanto a su número y cómo operaban, de manera que no tiene mucho que ver la teoría de los decanos de la India con la versión egipcia. A esta confusión se une el problema de las dodecatemorias, una división adicional de los signos creada por los caldeos. Las propiedades de ambas divisiones no estuvieron claras hasta que el trabajo de Abu Ma’shar, responsable del desarrollo completo de la teoría de los decanos, puso fin a las ambigüedades (Akopyan, 2017: 557).

Además, intenta demostrar que la teoría de los decanos es posterior a Tolomeo, para lo cual se fija en la conclusión 95 del Centiloquium, texto que, según Pico, está plagado de errores, entre ellos, el término $\pi \alpha \rho \alpha v \alpha \tau \dot{\lambda} \lambda \lambda o v \tau \alpha$, usado en la versión griega, no se corresponde con el latín decano. Por mor de este error, otros astrólogos habrían supuesto que Tolomeo compartía esta teoría astrológica (Akopyan, 2017: 557-558).

Otro de los aspectos que critica respecto al Centiloquium es la llamada teoría de las grandes conjunciones, que procede de la tradición islámica de la astrología y de la que nos ocuparemos in extenso más abajo. A este respecto, Pico pone de relieve las contradicciones flagrantes que observa entre los distintos autores en este punto tan importante. Así, según él, hay autores que consideran que la gran conjunción se produce entre tres planetas, Júpiter, Saturno y Marte, sin que tenga por qué tener ninguna relación con ningún signo del zodíaco -aunque normalmente se insistía en que la gran conjunción era más poderosa cuando coincidía con Aries-. Otros tenían en cuenta también otros signos, complicando aún más las predicciones. Pico refuerza su argumentación indicando que los cálculos astrológicos hechos para determinar esta teoría eran incorrectos, como demostraban las numerosas predicciones erróneas hechas a partir de ella, como la que hizo Abu Ma'shar sobre el fin del cristianismo para 1460; o la predicción de Abraham el Judío, que esperaba la llegada del Mesías para 1464, entre otras. Tras revisar el Tetrabiblos, Pico no encuentra ninguna mención a esta gran conjunción, de la que en cambio sí encuentra menciones en el Centiloquium, algo que él, nuevamente, atribuye a una mala traducción (Akopyan, 2017: 559-560).

Después de repasar estas y otras inconsistencias y debilidades de la teoría astrológica, Pico llega a tres conclusiones fundamentales: 1) la astrología judicial es un tipo de conocimiento falso, y contrapone a esta la «astrología matemática», que observa los efectos naturales sin pretender predecir el futuro; 2) las técnicas astrológicas también son falsas debido a la naturaleza errónea de la astrología y a las numerosas contradicciones y errores en los cálculos hechos por los astrólogos; 3) finalmente, las prácticas astrológicas varían notablemente entre la mayoría de las supuestas autoridades del arte astrológico (Akopyan, 2017: 563-564). 
Las duras y bien fundamentadas críticas de Pico, aunque recibieron la inmediata respuesta de los defensores de la astrología, entre ellos de Pontano, que a partir de 1501 comenzó a publicar una serie de refutaciones contra las mismas, como el De fortuna, removió los cimientos de la pseudociencia, hasta el punto de que un grupo de astrólogos, que podríamos incluir dentro del sector de los reformadores, admitieron que lo que Pico decía era verdad, por lo que trataron de construir una astrología más cuidada, cuyos fundamentos debían buscarse precisamente en el Tetrabiblos, libre de todas las supersticiones árabes (Campion, 2009: 105-106). Por esta razón Pico, sin pretenderlo, se convirtió en un referente, y en una fuente de inspiración, para todos aquellos que deseaban la refundación del arte astrológico.

Entre esos reformadores se encontraba el propio Kepler, que proponía abandonar toda la estructura técnica de la astrología, incluyendo los signos del zodíaco, y conservar solo lo que pudiera medirse, principalmente los movimientos planetarios. Su objetivo era llevar un registro de acontecimientos siguiendo los ciclos astronómicos y observar las correlaciones entre esos ciclos y los sucesos que se producían en la Tierra, para conseguir una astrología realmente útil que sirviera de base para hacer predicciones y gestionar el futuro para el bien común (Campion, 2009: 106).

Lo curioso del caso es que, "It was the reformers, who were all too aware of astrology's failures, who were to drive the astronomical discoveries of the next 200 years» (Campion, 2009: 106).

Defensor a ultranza del Tolomeo redivivo fue Girolamo Cardano, que se mostró muy crítico no solo con los astrólogos del Medievo, sino incluso con algunos antiguos, como Fírmico Materno, y contemporáneos, como el propio Pontano, autor de una traducción y comentario del Centiloquium, como ya se ha indicado. El motivo principal de su crítica, contenida en su comentario al Tetrabiblos IV, 10, es que todos los que ignoran los métodos del maestro alejandrino, cuando hacen predicciones, se limitan a señalar el significado individual de los signos celestes -Saturno en tal lugar significa tal cosa, Júpiter, tal otra-, cuando lo que deberían hacer es tener en cuenta todos esos significados individuales dentro de un conjunto, de modo que sea posible establecer relaciones entre ellos. Es lo que Cardano denominaba ratio commixtionis. se trataba de evaluar el modo en que las estrellas creaban ciertas mixtiones o relaciones entre sí, para lo cual había que tener en cuenta su colocación, cuáles son más fuertes y cuáles más débiles y qué característica de cada una predomina en un asunto o en otro (Bezza, 2014: 81).

Pero a pesar del optimismo de los reformistas, pronto se demostraron las carencias de la astrología tolemaica. En efecto, en lo relativo a la apotelesmática universal, es decir, en las predicciones que afectaban a países o regiones extensas, Tolomeo se basaba en los eclipses, sizigias y cometas, fenómenos todos ellos cuyos efectos eran de corta duración, o muy limitados geográficamente, o que, como en el caso de los cometas, ni siquiera eran regulares. Astrólogos de la categoría de Tommaso Campanella ya habían indicado las carencias de la doctrina tolemaica en este punto y su preferencia por la teoría de las grandes conjunciones de los tres planetas superiores, sobre todo de Saturno y Júpiter, para obtener pronósticos que afectaban a la historia o al orden social'5

${ }^{5}$ Mancus est Ptolemaeus in sua doctrina cum solis eclipsibus mutationes det, et initia rerum, cum enim istae sint parvae durationis, non nisi super res parvi temporis indicationis habent [...]. Oportet ergo causas potiores accipere, quod Albumasar cognovit, sed non perfecit (Campanella, 1629, vol. 2, part. 3, 1, 66). 
Esta teoría, de origen árabe, había sido expuesta por los astrólogos Al-Kindi, Mashallah y, sobre todo, Abu Ma’shar, en su obra Kitäb-al qirant (=De magnis coniunctionibus), tratado del que se publicaron ediciones latinas en Ausburgo, 1489, y Venecia, $1515^{6}$. Sostenía que cada veinte años los dos planetas superiores y más lentos, Saturno y Júpiter, protagonizaban una "gran conjunción", observándose con atención el signo zodiacal en que tenía lugar tal encuentro ${ }^{7}$. El propio Cardano, en su comentario al Tetrabiblos II, 9, a pesar de su defensa a ultranza de los contenidos del tratado tolemaico, confirma la teoría de las grandes conjunciones, al igual que hicieron la mayoría de los comentaristas de Tolomeo (Bezza, 2014: 83-84).

Entre las excepciones a esta aceptación general de la teoría de las grandes conjunciones se encuentra Lucio Bellanti, médico y astrólogo italiano, defensor de la visión tradicional de la astrología medieval y autor de varios tratados en defensa de la pseudociencia, entre ellos unas Responsiones in disputationes Johannis Pici, con las que respondía al ataque de Pico en sus Disputationes de una manera tan contundente y detallada que logró contener en un primer momento el impacto de las críticas de Pico contra la astrología (cf. Vescovini, 2014: 132). Bellanti reconocía que la teoría de las grandes conjunciones no formaba parte del auténtico Tolomeo -algo puesto de relieve ya por Pico, como hemos visto más arriba-, pues este solo pretendía explicar sucesos de la vida individual y no los relativos al mundo, en particular aquellos que fueran útiles para conservar la salud (Vescovini, 2014: 134). En esta misma línea, Bellanti se atrevió a criticar una de las obras de astrología más importantes de entonces, el De iudiciis de Guido Bonatti, el más importante astrólogo del siglo XIII, precisamente por tratar las grandes conjunciones que, supuestamente, precedían al nacimiento de las religiones, por considerarla falaz y errónea, por la incertidumbre y las dudas

${ }^{6}$ Cf. Hübner (2014: 21 y 29). Abu Ma’shar (o Albumasar, en su forma latinizada) fue el astrólogo árabe que más interés despertó no solo durante el Medievo, sino también en el Renacimiento. Además de su De magnis coniunctionibus, que ya había sido traducido al latín en el siglo XII, llamaron mucho la atención su «Pequeña introducción», traducida al latín en 1120 por Adelardo de Bath, y su "Gran introducción», libro que, aunque compuesto en el siglo IX, empezó a ejercer una gran influencia en el XII, llegando a ser traducido dos veces al latín y a convertirse en uno de los manuales de astrología más importantes del Medievo latino, debido a su detallada fundamentación teórica de la astrología, basada en la filosofía natural de Aristóteles, junto con una exposición muy detallada de todas las áreas de la astrología (cf. Blume, 2014: 339).

${ }^{7}$ Cf. Hübner (2014: 29). La teoría de las grandes conjunciones será invocada a menudo en el Renacimiento en el pronóstico de acontecimientos de gran repercusión política y social. Así, a partir de la conjunción de estos dos planetas en Escorpio en 1484 se pronosticó el nacimiento del Anticristo, y como en el horóscopo de Lutero figuraban estos dos planetas junto con otros tres en la novena casa de su horóscopo, se desató una viva y larga discusión entre astrólogos católicos (Gaurico) y protestantes (Melanchton) sobre el particular (Faracovi, 2014: 97); asimismo, para el año 1524, numerosos astrólogos anunciaron el final de los tiempos, a causa de un segundo diluvio universal, por la conjunción de Júpiter, Saturno y Marte en el signo de Piscis, lo cual provocó auténticos ríos de tinta, pues se publicaron no menos de 160 obras de 56 autores diferentes confirmando la profecía o rechazándola como ridícula (cf. Eamon, 2014: 141). 
a la hora de fijar con precisión las coordenadas celestes debido a la precesión de los equinoccios (cf. Vescovini, 2014: 135).

Fuertemente deudora de la tradición árabe, y sobre todo de Abu Ma’shar, al que cita a menudo, son los Pronostici que Domenico Maria da Novara, quien tuvo como ayudante a Copérnico, compuso para los años 1483 a 1504 como responsable de la cátedra de astronomía en la Universidad de Bolonia.

De entrada, los pronósticos de Novara pertenecen a la apotelesmática universal, pues sus predicciones afectan normalmente al rey, los príncipes, el pueblo y las clases sociales de una serie de ciudades italianas, empezando por Bolonia, es decir, se circunscriben a las tierras italianas, clasificadas según los principios de la corografía astral, es decir, según el signo zodiacal que las rige.

Por la época en que vive Novara, llama la atención la fuerte impronta que la astrología árabe presenta en su obra. Y, aunque conoce a Tolomeo, los textos que maneja son las versiones latinas aparecidas en el Medievo.

En cuanto a sus teorías astrológicas, según nuestro autor, las «revoluciones de los años del mundo» constan de tres partes: 1) los grados de las grandes conjunciones (y la progresión de sus lugares y la aplicación del lugar de la división) -un elemento de origen árabe, como ya hemos comentado-; 2) los eclipses de Sol y de Luna y la proporción de su oscurecimiento - un elemento tomado de Tolomeo, que lo trata en el libro II de su Tetrabiblos-; y 3) la entrada del Sol en el punto del equinoccio vernal y la conjunción y oposición de las dos luminarias junto a la disposición de los astros. Según Novara, hay que tener en cuenta estos tres principios al hacer los pronósticos, si se quiere saber por anticipado la calidad de los acontecimientos futuros (cf. Bònoli et al., 2012: 37).

Asimismo, para hacer los pronósticos del año propuesto tiene en cuenta cinco elementos: 1) la hora de entrada del Sol en el equinoccio vernal; 2) la sizigia que precede a dicha entrada; 3) las conjunciones ya pasadas de los planetas superiores; 4) las progresiones de los lugares radicales de las grandes conjunciones; 5) y la determinación del orbis magnus, según lo que enseñaba Albumasar (cf. Bònoli et al., 2012: 37).

En esencia, Novara no hace sino aplicar la doctrina que Albumasar expone en los primeros capítulos del primer libro de su De magnis coniunctionibus, donde prioriza los grandes ciclos y las conjunciones de los planetas superiores frente a los eclipses y sizigias de la doctrina tolemaica, que considera claramente secundarios.

Un concepto fundamental de la astrología de entonces, también de origen árabe, que emplea Novara es el llamado orbis magnus, una especie de natividad del mundo, que se situó 279 años antes del diluvio, es decir, en el año 3101 a.C., a partir de la gran conjunción entre Saturno y Júpiter. De esta conjunción procede la doble cronocratoria $^{8}$ de las constelaciones y los planetas: la de las constelaciones empezaría

${ }^{8}$ La cronocratoria, tal como explica Manilio en Astron. 3, 510 ss., es un sistema por el cual se relacionan las estructuras temporales (años, meses, días y horas), con los signos astrológicos (constelaciones, grados, planetas). 
en Cáncer y la de los planetas en Saturno. De esta manera se iniciarían unos ciclos de 360 años de duración, cada uno de los cuales estaría gobernado por un planeta y un signo zodiacal. Este ciclo de 360 años es propiamente el orbis magnus. Este ciclo contiene todo lo sucedido en el periodo en cuestión, por eso hay que empezar por ahí. En el pronóstico de 1484, según Novara, el orbis magnus de entonces sería el XIV, cuyo dominio corresponde a la Luna entre los planetas y a Leo entre los signos zodiacales (cf. Bònoli et al., 2012: 46-49).

Otro punto de su doctrina, esta vez relacionado con la teoría de las grandes conjunciones, es el de la profectio. Y es que, en las conjunciones de los planetas superiores, dado que pasa mucho tiempo entre una y otra, el astrólogo debería indicar en qué momento se producen sus efectos y si estos van a suceder una o más veces. Para ello se emplea esta técnica, que consiste en asignar un año a cada signo que sigue al signo de la conjunción. Asimismo, se supone que habría una doble profectio, la del lugar de la conjunción y la de su horóscopo, de las cuales se obtienen pronósticos diferentes: de la primera se pueden extraer predicciones sobre la situación general del pueblo y todo lo concerniente al clima; de la segunda, predicciones sobre los reinos y los cambios de religión o doctrina (cf. Bònoli et al., 2012: 52-55).

Por último, un concepto particular de Novara es lo que él llama revolubilia tempora, que son los tiempos que retornan a un estado inicial y que se pueden asimilar a los periodos naturales del tiempo. Estos tempora serían cuatro: las revoluciones de los años del mundo, las de las fundaciones de ciudades, los eclipses y las sizigias (cf. Bònoli et al., 2012: 55).

La doctrina de los años del mundo es también de origen arabo-oriental, por las fuentes que Novara cita, a saber, Abu Ma’shar, Al-Kindi e Ibn Ezra, entre otros. Una cuestión relacionada con este tema es el modo de determinar el dominus anni: para algunos, sólo se debía considerar el Sol en Aries, mientras que otros proponían las sizigias. Novara, al menos en sus primeros pronósticos, estaba de acuerdo con los primeros (cf. Bònoli et al., 2012: 55-58).

Respecto a las fundaciones de ciudades, Novara suele ofrecer juicios anuales sobre ciudades cuyo momento de fundación o restauración era conocido, a saber, Bolonia, Venecia y Florencia. Para establecer el pronóstico, había que determinar primero la profectio del ascendente de la ciudad para el año en cuestión y luego precisar la revolutio annorum de la ciudad. En estos casos, se tiene en cuenta la corografía astral tal como la expuso Tolomeo en Tetrab. II, 3 (cf. Bònoli et al., 2012: 58-61).

Finalmente, respecto a eclipses y sizigias, en Novara tienen el carácter secundario que ya hemos comentado. No obstante, nuestro autor suele servirse de revoluciones y sizigias para emitir sus pronósticos, teniendo en cuenta los juicios derivados de cada una (cf. Bònoli et al., 2012: 61-63).

En fin, esta confluencia y complementariedad, a veces, entre fuentes clásicas y árabes también se registra en el ámbito de la astronomía. Así, a modo de ejemplo, en su análisis de las fuentes usadas por Copérnico en su De revolutionibus, Vernet (2000: 70 ss.) destaca, en primer lugar, como era de esperar, la Sintaxis matemática o Almagesto de Tolomeo, cuya lectura debió ser muy atenta, pues su De revolutionibus demuestra que Copérnico dominaba perfectamente todos los métodos matemáticos utilizados por el alejandrino, así como que la mayoría de las observaciones de 
la Antigüedad que conoce y emplea proceden de la obra de este. Pero junto al autor griego, fueron fundamentales para Copérnico los autores árabes Tābit b. Qurra, que escribió un Canon revolutionis anni y el De motu accesionis et recesionis, Battāni, autor de un De motu stellarum, y, sobre todo, Azarquiel, uno de los astrónomos más importantes de la historia, que dirigió el equipo que redactó las Tablas de Toledo, base de las Tablas alfonsinas. Su nombre se cita sobre todo en relación con los problemas de la longitud de los distintos tipos de año, de la precesión y de la trepidación?.

Aunque la recepción de Tolomeo constituye la marca distintiva de la astrología renacentista, queremos hacer también una mención más breve a los otros dos grandes astrólogos de la Antigüedad, Manilio y Fírmico Materno.

Manilio fue redescubierto en 1417, al mismo tiempo que el poema de Lucrecio, por Poggio Bracciolini, durante su asistencia al concilio de Constanza. El honor de la editio princeps puede corresponder tanto a la de Regiomontanus, aparecida en Nuremberg a finales de 1473 o comienzos de 1474 (M. Manilii Astronomicon [...), justo antes de su prematura muerte, como a otra anónima, aparecida en Bolonia en 1474 (M. Manilii mathematici astronomicon ad Caesarem Augustum). El primer comentario renacentista del autor latino corresponde a Lorenzo Bonincontri, Laurentii Bonincontrii Miniatensis in C. Manilium Commentum (Roma, 1484). Muy importante fue también la edición y el comentario de Joseph Justus Scaligero, Astronomicon libri quinque, Josephus Scaliger recensuit, ac pristino ordine restituit. Eiusdem J. Scaligeri commentarius in eosdem libros, \& castigationum explicationes (París, 1578-1579, con reimpresión en Heidelberg, 1590), que él consideraba como uno de sus mejores trabajos (Hübner, 2014: 50).

La opinión de Scaligero sobre Manilio tiene que ver más con sus dotes de poeta que con sus prestaciones como astrólogo. Compara su estilo con el de Ovidio, aunque considera que supera a este en maiestas. Así, en la p. 18 de su comentario dice: poeta ingeniosissimus, nitidissimus scriptor, qui obscuras res tam luculento sermone, materiam morosissimam tam iucundo charactere exornare potuerit, Ovidio suavitate par, maiestate superior (Hübner, 2014: 50).

Y esta admiración más hacia el poeta que hacia el astrólogo será nota común al menos durante el periodo renacentista. Así, Pico della Mirandola salva a Manilio de su condena de la pseudociencia por su calidad como poeta. Por razones poéticas Bonincontri trató extensamente el tema de los planetas, que Manilio omitió en

${ }^{9}$ Aunque entre sus fuentes Copérnico cita al filósofo pitagórico Filolao (s. VI a.C.) como una autoridad para la teoría de que la Tierra se movía en el espacio, es dudoso que conociera su obra. En cambio, sí es más probable que conociera al astrónomo griego Aristarco de Samos, que ya había defendido la idea de que la Tierra giraba alrededor del Sol, así como a Marciano Capela, que afirmaba que Mercurio y Venus orbitaban alrededor del Sol. Por supuesto, también debió influir en él la idea de Ficino del Sol como centro del universo, expresada ya en sus traducciones de Hermes y Orfeo y a través de su concepto del amor, que situaba al hombre en el centro, como nexo de las jerarquías espirituales cósmicas (cf. Campion, 2009: 110). 
su tratado. Algo similar hizo su amigo Giovanni Pontano al comienzo de su Urania, el mejor poema sobre las estrellas escrito durante el Renacimiento e imitado a menudo (Hübner, 2014: 50-51) ${ }^{10}$.

Otra influencia curiosa que ejerció la obra de Manilio fue en el terreno del arte, en concreto, en las pinturas murales de temática astrológica del Palazzo Schifanoia de Ferrara, donde los motivos representados aúnan la mitología concerniente a los antiguos dioses y su conexión astrológica, algo a lo que contribuyó grandemente el poeta latino. En concreto, en estas pinturas se da una gran importancia a la astrología de las estrellas fijas, mientras que los planetas no desempeñan ningún papel relevante. Así, en el registro superior, situado en la zona oscura de los cielos, aparecen representados los doce dioses olímpicos conduciendo unos vehículos ricamente adornados. Por debajo de ellos se sitúan numerosas figuras y episodios secundarios. Según la crítica, las figuras de los dioses estarían encarnando los poderes atribuidos a cada uno de los signos zodiacales, lo que ha llevado a sugerir como fuente de inspiración Astron. 2, 439 ss., donde Manilio habla precisamente sobre la tutela de los dioses sobre los signos (Blume, 2014: 343).

Respecto a Fírmico Materno, los primeros manuscritos de su De nativitatibus sive matheseos libri VIII son del siglo XI, aunque su uso parece que se extendió mucho más a partir del XIII, a la vista del número de copias de esa época conservadas. De hecho, la edición de Kroll-Skutsch-Ziegler contaba hasta 43 manuscritos, a los cuales P. Monat, autor de la edición y traducción de Les Belles Lettres añade 6 más (Monat, 2002: 26). Por ello no es de extrañar que sea mencionado en un gran número de ocasiones durante el Medievo como una de las grandes autoridades de la astrología, parangonable incluso con Tolomeo. Así, aparece citado entre los astrólogos por Guillaume de Conches en su De philosophia mundi; lo elogia Honorius d'Autun, en su De philosophia mundi, II, 5 (= PL 172, col. 59); Guillaume de Malmesbury lo cita en su De gestis regum Anglorum (PL 179, col. 1138B), para decir que Gerbert había estudiado su obra en España, y en su De gestis pontificum Anglorum, para decir que Girard, arzobispo de Évreux, entre otros pecados, se había entregado a la lectura de Fírmico (Monat, 2002: 25). Su obra se encontraba entre los libros propiedad de Petrarca (Hübner, 2014: 21).

Ya en el Renacimiento, extractos de la Mathesis fueron impresos en 1488 en Ausburgo, en una obra titulada Astrolabium Planum, cuyo editor fue Johannes Angeli, donde encontramos todo el libro III, una gran parte del IV y más o menos un tercio del V, con el orden de los capítulos algo cambiado. La editio princeps fue impresa en Venecia en 1497, a cargo de un editor desconocido, que probablemente utilizó la edición parcial de Angeli (Monat, 2014: 31). En 1499 Aldo Manutius editó la Mathesis junto con otros muchos textos de temática astral, no siempre astrológica, como Manilio, los Fenómenos de Arato en las versiones de Germánico, Cicerón

\footnotetext{
${ }^{10}$ Sobre la recepción del poema de Manilio, cf. Hübner (1980: 56-61).
} 
y Avieno y los Commentaria in Aratum de Teón, entre otros. La edición corrió a cargo de Pescennius Franciscus Niger. Se le achaca que, llevado por un afán excesivo de corrección, dio un tono ciceroniano al latín tardío de nuestro autor. En el XVI, el texto de Fírmico de la Aldina fue reproducido con algunas correcciones al texto, siendo la más duradera la de Basilea, de 1533 (con una segunda edición en 1551), a cargo del médico y astrólogo N. Pruckner, bajo el título Iulii Materni [...] Astronomicon lib. VIII per Nicolaum Prucknerum astrologum nuper ab innumeris mendis vindicati, en la que además de Fírmico se pueden encontrar otros textos astrológicos de interés médico. Curiosamente es esta edición la que cita Bouché-Leclercq (cf. Monat, 2002: 31-32 y Hübner, 2014: 21-22, n. 36).

Respecto al empleo de Fírmico Materno en el Renacimiento, de entrada, Pico ya señaló diversos errores en su doctrina astrológica ${ }^{11}$. Ya hemos observado más arriba cómo Cardano lo criticaba como fuente; Pontano lo utilizó para completar y verificar pasajes perdidos de los Astronomica de Manilio (Hübner, 2014: 21). En fin, el médico francés Antoine Mizauld (ca. 1512-1578), en su Aesculapii et Uraniae medicum et astronomicum ex colloquio conjugium, publicado en Lyon en 1550, obra en la que, a través del diálogo entre el dios de la medicina Asclepio y la diosa del cielo Urania, puso las bases teóricas de su medicina astral, menciona a Fírmico Materno junto con Tolomeo como la fuente principal en materia astrológica y astronómica (Hirai, 2014: 276) ${ }^{12}$.

En relación también con Fírmico Materno, durante el Renacimiento se le atribuyó el denominado modus aequalis, una de las siete formas que, según Placidus Titi (mediados del siglo XVII) existían de determinar la «domificación», es decir, de establecer las doce casas astrológicas. Tal modus consistía en dividir el círculo zodiacal en doce partes iguales por medio de círculos que pasaban por los polos del zodíaco. Este procedimiento, que no es de origen árabe, Cardano, en su juventud, llegó a apoyarlo, aunque después se decantó por el de Alcabicio, que era el mismo usado por Regiomontanus, por considerarlo matemáticamente más correcto (Bezza, 2014: 63-65).

Si la refundación de la astrología renacentista se basó en un Tolomeo liberado de los elementos extraños incorporados a sus doctrinas durante el Medievo, muy importante fue también la recuperación del Corpus Hermeticum, una colección de al menos 18 textos escritos en griego, atribuidos al dios Hermes Trismegisto, versión helénica del dios egipcio Tot, surgido en el ambiente de sincretismo religioso y cultural que se vivía en el Egipto helenístico. Respecto a su datación, la más aceptada es la que propuso Scott, que los situaba entre los ss. II-III d.C., por ser esta la época en que empezaron a ser citados de forma explícita por los autores cristianos (cf. Renau Nebot, 1999: 37). Su contenido es muy diverso e incluye cuestiones filosóficas afines al platonismo, elementos relacionados con la astrología y la alquimia y otros ya de naturaleza más bien mística.

${ }^{11}$ Motivados sin duda por su afán por combinar y sincretizar tradiciones muy heterogéneas no siempre bien dominadas ni comprendidas (Monat, 2002: 20).

${ }^{12}$ Sobre el tema cf. también Rinaldi (2002). 
Todo este abigarrado cuerpo de doctrinas se conoce con el nombre genérico de Hermetica, que en su variante culta ${ }^{13}$ podría definirse como una serie de comentarios que realizó una comunidad relativamente organizada a partir del conglomerado religioso egipcio de época helenística y romana, cuyos contenidos incluían elementos de magia, alquimia y astrología, expresados sobre todo en los términos del medioplatonismo, pero que incluían otros «lenguajes» como el gnóstico o el judío (Renau Nebot, 1999: 26).

De cara al Renacimiento, el hermetismo constituyó algo más que una fuente para los tratadistas de la astrología, de la magia o del ocultismo en general, ya que permeó la obra y las ideas de autores como Marsilio Ficino, Pico della Mirandola o Giordano Bruno.

En cuanto al redescubrimiento de estos textos, el punto de partida fue un manuscrito griego con catorce tratados breves (el actual Laurentianus LXXI 33 A), traído en 1460 a Florencia desde Macedonia por Leonardo de Pistoia y vendido a Cosme de Medicis. Este encargó su traducción al latín a un joven Marsilio Ficino, que la terminó en abril de 1463. El manuscrito de Ficino se encuentra en la Biblioteca Laurentiana (es el Laurentianus 71, 33 XIV). Como afirma Eugenio Garin (1981: 95), nunca se ponderará lo suficiente la importancia de la traducción de estos escritos por Ficino.

Antes de su recuperación por los occidentales, el hermetismo había sobrevivido en el mundo islámico, sobre todo en los siglos XI y XII, en los heterodoxos sabeos, en Suhrawardi (maestro persa del siglo XII y uno de los principales representantes de la gnosis musulmana), en Al-Kindi y en otros autores (Ferrer Ventosa, 2019: 8).

Ficino, que creía que se trataba de capítulos de una misma obra, la tituló con el nombre del primer tratado, Pimander, adaptación latina del griego Poimandres (Kingsley, 2000: 43). Ya en su forma manuscrita su éxito fue notable, y fue impreso en 1471 con el título de Mercurii Trismegisti Pimander seu liber de potestate ac sapientia Dei. En 1469 se publicó la editio princeps del Asclepius ${ }^{14}$. Todos estos textos constituyen los catorce primeros textos del Corpus Hermeticum moderno.

${ }^{13}$ Uno de los principales estudiosos del tema, André-Jean Festugière (1967: 30), estableció dos tipos de hermetismo, uno popular, o técnico, con escritos ocultistas, escritos a partir del siglo III a.C. y dados a conocer a partir del siglo I a.C., que trataban de astrología, alquimia, magia, de botánica mágica y de medicina ocultista, basados en las correspondencias y las simpatías o antipatías, todas ellas de origen estoico; y otro culto, o filosófico, compuesto por una serie de textos filosóficos a partir de finales del siglo I d.C., integrado por el Corpus Hermeticum, el Asclepius (atribuido falsamente a Apuleyo), los extractos herméticos recogidos sobre el 490 por el sabio bizantino Estobeo y los textos de Nag Hammadi, procedentes de una biblioteca gnóstica copta. A pesar de esta división, en los Hermetica cultos también se encuentran textos de temática mágica, astrológica o alquímica. Sus autores serían seguramente griegos del Egipto helenizado.

${ }^{14} \mathrm{El}$ Asclepius fue conocido en el Medievo europeo, sobre todo a partir del siglo XI, y citado por pensadores como Tomás de Aquino, Abelardo o Alberto Magno. Como curiosidad, ya en el Renacimiento, el Discurso sobre la dignidad del hombre de Pico della Mirandola comienza con la cita: Magnum 
Poco después Lodovico Lazzarelli (1447-1500) descubrió un nuevo manuscrito griego, que tradujo al latín y que se publicó en 1507 con el título de Aesculapii definitiones ad Ammonem regem, que constituye el actual $\mathrm{CH}$ XVI.

En 1554, Adrien Turnèbe publica en París Mercurii Trismegisti Poemander, seu de Potestate ac sapientia divina. Aesculapii definitiones ad Ammonem regem, que comprende los actuales $\mathrm{CH}$ I-XIV, XVI-XVIII, que constituye la editio princeps del texto griego. Asimismo, como apéndice de $C H$ XIV añadió tres extractos de la antología de Estobeo, los actuales $S H$ I, SH IIA y un fragmento del Asclepio.

En 1574, François de Foix publica en Burdeos una nueva edición, Mercurii Trismegisti Pimandras utraque lingua restitutus. D. Francisci Flussatis industria, que reproduce la edición de Turnèbe, pero convirtiendo los tratados en capítulos y haciendo del apéndice a $C H$ XIV el capítulo XV.

El primer comentario del Corpus fue publicado en Cracovia, entre los años 1585-1590, por Annibale Rosseli, bajo el título Pymander Mercurii Trismegisti, en 6 volúmenes, que recogía pasajes seleccionados de $C H$ I-VII y del Asclepio.

El último editor del XVI del Corpus fue Francesco Patrizzi, que publicó dos ediciones: la de Ferrara, de 1591, Nova de universis Philosophia, y la de Hamburgo, de 1593, Magia philosophica. Zoroaster et eius 320 oracula caldaica; Asclepii dialogus et philosophia magna; Hermetis Trismegisti Poemander et alia miscellanea, que comprenden ya los dieciocho tratados del Corpus, los extractos de Estobeo, el Asclepio y los fragmentos de Cirilo ${ }^{15}$.

Durante el Renacimiento fue communis opinio que el autor de estos tratados, al igual que de otros como la Tabla de Esmeralda, fue Hermes Trismegisto, un personaje mítico, supuesto sacerdote del dios egipcio Tot, que habría sido contemporáneo del propio Moisés, de Noé o incluso Abraham. Por su parte, Ficino creía que el Corpus Hermeticum era una buena prueba de la existencia de una Prisca Theologia, una especie de religión revelada, conocida por los antiguos, que se conservaría en el núcleo de todas las religiones (Ferrer Ventosa, 2019: 9).

Por su parte, en 1614, Isaac Casaubon, en su De rebus sacris exercitationes XVI, en concreto, en Exercitatio I, p. 71 afirma: Nos igitur, quod ad prius, affirmamus, in eo libro contineri non Aegyptiacam Mercurii doctrinam, sed partim Graecam e Platonis et Platonicorum libris, et quidem persaepe ipsis eorum verbis, depromptam, partim Christianam e libris sacris peritam. Es decir, que la supuesta doctrina egipcia de

miraculum est homo (Asclepius, 6), que se acabó convirtiendo en una auténtica divisa renacentista. También lo citaron Agrippa y Campanella. La importancia de la frase radica en que, en verdad, resume muy bien la antroposofía hermética, expresada en ideas tales como que el hombre es digno de admiración y más eminente que cualquier otro ser, o que el hombre está por encima de los dioses o al menos es igual a ellos (cf. Ferrer Ventosa, 2019: 10; Renau Nebot, 1999: 433, n. 11).

${ }^{15}$ Sobre las distintas ediciones y traducciones del Corpus Hermeticum, cf. Renau Nebot (1999: 32-34). 
Hermes/Mercurio, no era sino una doctrina griega procedente, de un lado, de Platón y los platónicos, y, de otro, de las Sagradas Escrituras. Esta idea, que no se impuso hasta finales del XVII, chocó radicalmente con el catolicismo, que colocaba el Corpus Hermeticum entre los textos proféticos (cf. Yates, 1983: 452 ss.).

Las implicaciones del trabajo de Casaubon, armado con el método filológico, fueron demoledoras, pues no solo acabó con la construcción neoplatónica, que postulaba el culto por los prisci theologi, entre los cuales se encontraba Hermes Trismegisto, sino que también arrasó con la posición mantenida hasta entonces por la magia y su fundamentación hermético-cabalística, apoyada en una supuesta filosofía y cabalística «egipcias», y por supuesto también con el hermetismo cristiano, que había florecido a lo largo del siglo XVI (Yates, 1983: 452).

Y aunque es cierto que las ideas de Casaubon ya fueron objeto de crítica en su tiempo, como las que le dirigió el neoplatónico inglés Cudworth, que, aunque admitía que había interpolaciones cristianas, eso no anulaba el fondo egipcio de esos textos (cf. Hofmeier, 2002), algo que han confirmado especialistas modernos (cf. Ferrer Ventosa, 2019: 16), el daño ya estaba hecho, y con él el descrédito de las doctrinas herméticas.

Respecto a la influencia concreta del Hermetismo, este formó parte junto con el neoplatonismo, la magia y la cábala judía del trasfondo filosófico de algunas de las famosas 900 tesis (1486) de Pico della Mirandola, en particular de las que consagró a la magia (Vescovini, 2014: 132).

También ejerció una influencia muy notable en Giordano Bruno, tema este al que Frances Yates (1983) ha dedicado un amplio estudio en el que no solo viene a defender la relación con el hermetismo de todos los trabajos de Bruno sobre la memoria, sino que, quizás exageradamente, se presenta su obra como una variación dentro de la tradición hermético-cabalística, algo que la crítica más reciente ha matizado (cf. Ferrer Ventosa, 2019: 11, n. 29).

Uno de los desarrollos más curiosos que llevó a cabo Bruno, en los que mezcló contenidos astrológicos y mágicos con las doctrinas herméticas, es un complejo, y oscuro, sistema mnemotécnico, del que se ocupó en su momento Yates (1983: 224-235).

Este sistema está recogido en dos libros publicados en París en 1582, ambos en forma de diálogo, el De umbris idearum y el Cantus Circaeus. Entre las fuentes principales de estos tratados cabe citar el De vita coelitus comparanda de Ficino, sobre todo del primero, y el De occulta philosophia de Cornelio Agrippa.

El De umbris idearum se articula en torno a 150 imágenes que sirven de fundamento a su propuesta de sistema mágico de la memoria. De ellas, las 36 primeras imágenes representan a los decanos; le siguen 49 imágenes planetarias, siete por cada uno de los planetas; menciona a continuación 28 imágenes para las mansiones de la luna y una del Draco lunae, finalmente, se incluyen 36 imágenes más, asociadas con las doce casas en las que se divide el horóscopo. Si los tres primeros grupos de imágenes proceden claramente de Agrippa, estas últimas podrían ser de creación propia bruniana.

Estas imágenes irían colocadas en una especie de rueda y se corresponderían con otras ruedas en las se hallaban representados todos los contenidos del mundo físico terrestre y todo el conocimiento humano acumulado a lo largo de los siglos. Este último estaría representado con las imágenes de 150 grandes hombres e inventores. 
De esta manera, el que estuviera en posesión de tal sistema podría reflejar en su propia mente todo el universo de la naturaleza y del hombre.

Por su parte, el Cantus Circaeus recogería una serie de conjuros pronunciados por la maga Circe, ad memoriae praxim ordinatus, dirigidos a los planetas, seguido de un arte de la memoria. Su objetivo sería disponer la imaginación del adepto para recibir improntas de las imágenes planetarias, preliminar necesario para la memoria mágica.

Otro de los grandes genios del Renacimiento que también recibió la influencia del hermetismo fue el inglés John Dee (1527-1608/1609), que llegó a ser consejero de la reina Isabel, y que en opinión de Yates (1982: 276), gracias a su trabajo, el hermetismo se convirtió en algo así como en la filosofía de la época isabelina. A pesar de la fama posterior que Dee tuvo de "vain, credulous, and enthusiastic», en su tiempo fue un ejemplo perfecto de esos humanistas del Renacimiento que fueron capaces de aunar la astronomía, las matemáticas, la astrología, la magia y el ocultismo.

Es conocida también la mención que hizo Copérnico en su De revolutionibus, 1, 10 a Hermes Trismegisto: In medio uero omnium residet Sol. Quis enim in hoc pulcherimo templo lampadem hanc in alio uel meliori loco poneret, quam unde totum simul possit illuminare. Siquidem non inepte quidam lucernam mundo, alii mentem, alii rectorem uocant. Trismegistus uisibilem Deum, Sophoclis Electra intuentem omnia ${ }^{16}$. Esta referencia pudo venir no solo de la traducción ficiniana de los escritos herméticos, sino también de la tradición árabe que pasó a Occidente a través de las traducciones latinas de Albumasar (Vernet, 2000: 52). En el caso de Copérnico, la inclusión de la mención a Hermes se produce en el contexto de la mención a otras fuentes antiguas y medievales, por lo que su objetivo último debía ser demostrar que sus ideas no eran tan nuevas o radicales como podrían parecer a primera vista, ya que tenía fuentes clásicas que legitimaban sus propios puntos de vista (cf. Lehrich, 2007: 42).

Un texto fundamental en el Renacimiento, vinculado con el hermetismo, pero dedicado sobre todo a la magia talismánica de origen astrológico fue el Picatrix, un tratado de origen árabe, el Ghāyat al-hakim, La finalidad del sabio, compuesto en la España musulmana en la primera mitad del siglo X o en el XI. Del texto se hizo una primera versión al hebreo (Ben-Zaken, 2020: 1034), y bajo Alfonso X el Sabio se hicieron dos versiones: una al castellano, en 1256, de la que apenas se conservan algunos fragmentos, y otra posterior al latín, hecha entre 1256 y 1258. Se ha atribuido falsamente su autoría al matemático, alquimista y astrónomo andalusí Maslama al-Majrîti (ca. 950-1008). La versión árabe fue descubierta sobre 1920 por el orientalista alemán Wilhelm Printz. En 1933 Hellmut Ritter editó el texto, que fue traducido al alemán en 1962 por Ritter y por Martin Plessner.

Fue la versión latina confeccionada durante el Medievo la que se extendió por Europa, sobre todo entre los siglos XV y XVII. La obra, que comprende cuatro libros,

${ }^{16}$ Citamos por la edición de Nuremberg, 1543. 
es un tratado de nigromancia (Picatrix I, II, 1), entendida como el conocimiento de todo lo que se oculta a la comprensión de los hombres, que son incapaces de percibir cómo se llevan a cabo ni de qué causas provienen esas cosas ocultas: Et generaliter nigromanciam dicimus pro omnibus rebus absconditis a sensu et quas maior pars hominum non apprehendit quomodo fiant nec quibus de causis veniant (Picatrix I, II, 1) ${ }^{17}$. Sería el resultado de la compilación de al menos doscientos libros, según se afirma en el prólogo ${ }^{18}$, de pequeños tratados mágicos, astrológicos y herméticos surgidos en el ambiente sincretista del Próximo Oriente medieval a partir de textos y tradiciones muy diversas. Su lectura no es fácil por presentarse, en apariencia, como una sucesión de recetas mágicas, tras la cual, sin embargo, hay un trasfondo filosófico (cf. Ben-Zaken, 2020: 1036).

Uno de los objetivos fundamentales del tratado es la búsqueda de una doble legitimidad: teórica -comprender la eficacia de prácticas de muy diverso tipo-y moral -liberar la magia de sus relaciones con la demonología-. La legitimidad teórica se basa en las relaciones simpáticas que mantienen entre sí las partes del universo, el mundo sublunar y el supralunar; la legitimidad moral se apoya en última instancia en el fundamento divino en el que se basa toda la realidad (Fauquier, 2000: 131-132).

Esta legitimación de la magia se consigue, en parte, con el neoplatonismo, que presenta la estructura teórica ideal para dar sentido a la acción mágica (Fauquier, 2000: 136), pero también a través de Dios, fuente de todo poder y de todo conocimiento (Fauquier, 2000: 139).

En cuanto a su difusión en el Renacimiento, de entrada, por el gran número de manuscritos conservados en las bibliotecas de París, Florencia, Oxford o Londres, entre otras, todos ellos copiados entre los siglos XV y XVII, hemos de suponer que su difusión se produjo principalmente en torno a 1450. Respecto a su importancia, Garin (1981: 76) lo consideraba tan fundamental como el Corpus Hermeticum o la obra de Abu Ma’shar para comprender una parte esencial de la producción del Renacimiento, incluyendo las artes figurativas. Zambelli (2007: 9) destaca su contribución al surgimiento de la magia natural y cómo fue leído y asimilado antes incluso de la recuperación de los textos herméticos.

A este respecto, parece que fueron los humanistas italianos los primeros en prestarle más atención ${ }^{19}$. Entre ellos, uno de los primeros fue Galeotto Marzio

\footnotetext{
${ }^{17}$ Citamos por la edición de Pingree (1986). Al hablar de 'nigromancia' en el Picatrix no debemos confundirlo ni con magia negra, ni con necromancia propiamente dicha, «mais bien d'une magie dégagée de ses fondements maléfiques et démoniaques» (cf. Fauquier, 2000: 146).

${ }^{18}$ Cf. Pingree (1986: 1): Sapiens enim philosophus, nobilis et honoratus Picatrix, hunc librum ex CC libris et pluribus philosophie compilavit. Se ha especulado mucho sobre el origen del curioso nombre de su supuesto autor, Picatrix, con el que se conoce al tratado, siendo la opinión más extendida la de que sería una deformación del nombre árabe Buqatris, adaptación a su vez del griego Hypocrates (cf. Ben-Zaken, 2020: 1035), o quizás Harpocración, opiniones estas que no convencían mucho a Pingree (1986: XV, n. 3).

${ }^{19}$ Sobre la influencia de este tratado en la Italia renacentista, cf. Compagni (1977).
} 
(1427-1499), en el contexto de su obra médica, filosófica y astrológica (Attrell - Porreca, 2019: 5). Marsilio Ficino, que lo tuvo muy presente para elaborar sus teorías de la magia natural y astral para su De vita coelitus comparanda (Attrell - Porreca, 2019: 5), contribuyó, gracias a su autoridad, a hacer resurgir en Europa las prácticas astrológicas, teúrgicas y necrománticas de magia astral (Vescovini, 2014: 121).

En un interesante trabajo, Ben-Zaken (2020) ha detectado la influencia del Picatrix en tres autores renacentistas de la importancia de Ficino, Agrippa y Campanella. Los tres tienen en común el haber intentado convertir la magia natural en una alternativa a la filosofía de la naturaleza, presentándola como práctica científica, enraizada en tradiciones no europeas.

En el caso de Ficino, Ben-Zaken (2020: 1039) sostiene que este hizo una lectura muy selectiva del Picatrix, debido quizás a que tuvo entre sus manos un manuscrito incompleto, que comprendería los libros 3 y 4, o incluso una colección de excerpta. Además, descartó la mayor parte del contenido del mismo por considerarlo supersticioso. En fin, cuando se sirve de contenidos procedentes de la obra los atribuye a los «árabes» o los cita sin mencionar su fuente.

Respecto a usos concretos, Ben-Zaken (2020: 1039-1046) postula que la idea ficiniana de un cosmos animado por una suerte de alma universal, conectada con todo, incluso con aquellas cosas que se encuentran separadas unas de otras, toma muchos elementos del anima mundidel Picatrix, tal como se expone en el libro 4, que se manifiesta como una fuerza que genera movimiento, como fenómeno espiritual que provoca que los objetos se muevan de modo natural y no por accidente. Por su papel de agente mediador entre los cuerpos, dicha anima debe estar situada en medio del orden cósmico. Ficino habría adoptado este punto de vista para reemplazar la metafísica aristotélica. Pero, además, con el concepto de anima mundi arroja luz sobre lo que eran conocimientos y prácticas ocultas, transformando así lo oculto en una subcategoría de la filosofía natural.

Respecto a Cornelio Agrippa, no se sabe muy bien cómo pudo entrar en contacto con el tratado, si bien es posible que, durante el curso que impartió en Dole sobre la obra De verbo mirifico de Johann Reuchlin, los elementos que este tomó del Picatrix le animaran a consultar dicho tratado. La razón última por la que lo utilizó fue para legitimar la práctica de la filosofía natural. La obra donde la influencia es más notoria es su De occulta philosophia libri tres, compuesta en la primera década del XVI, pero publicada solo en 1531-1533 (Ben-Zaken 2020: 1046).

Entre los elementos que toma del Picatrix, uno de los más importantes es la figura del mago natural, el virtuoso, que no solo debe conocer el mundo natural, sino también adquirir las habilidades precisas para extraer los secretos del mismo, tal como se exponen en Picatrix III, 12. Agrippa lo utilizó como fundamento de su De occulta philosophia, al afirmar que la magia natural es una ciencia basada en exploraciones de primera mano de los secretos de la naturaleza. Sin embargo, la influencia más directa se daría cuando Agrippa describe las virtudes y habilidades que deben poseer los que practican la magia natural. Otro elemento procedente del Picatrix sería la noción del mago como aquel que es capaz de mezclar temas, disciplinas y prácticas diferentes, el mago como un agente que conecta el mundo superior e inferior. En fin, la propia idea del sol como fuente de todas las entidades físicas o espirituales aplicada al arte 
de fabricar talismanes, de manera que, si uno fuera capaz de crear una imagen que encapsulara las cualidades del sol, esta tendría un gran poder (Ben-Zaken, 2020: 1048-1052).

En el caso de Campanella, tampoco está claro cómo pudo entrar en contacto con el Picatrix, aunque es evidente que debió de ser con uno de los manuscritos en circulación de la obra antes de su entrada en prisión en 1598, pues la obra en la que más influyó, La città del sole, fue escrita en 1601 (Ben-Zaken 2020: 1055). Hay que advertir que, aunque el Picatrix nunca es mencionado, no es difícil confirmar su influencia.

Como ya se ha indicado, la influencia más palpable se detecta en su obra utópica La città del sole, donde se mezclan la magia natural, el arte de los talismanes, la ciencia experimental y hasta el heliocentrismo. La obra versa sobre un pueblo, los Solaris, que habitarían la isla de Taprobane, en el Índico, procedentes de la India, y que practicarían la magia natural. Lo más curioso es que en el Picatrix (IV, 3) se menciona una utópica ciudad de filósofos, adoradores del sol que usaban talismanes para garantizar el orden político. Se trataría de una ciudad construida por Hermes en el este de Egipto, con una ciudadela con cuatro puertas, cada una de las cuales estaba guardada por una imagen de animal: un águila, un toro, un león y un perro. Y alrededor de la ciudad colocó imágenes, gracias a las cuales los habitantes eran virtuosos y libres de pecado. La ciudad se llamaba Adocentyn, y sus habitantes eran grandes conocedores de las ciencias antiguas, en particular de la astronomía.

En opinión de Ben-Zaken (2020: 1060), La ciudad del sol de Campanella no sería sino un homenaje a las prácticas políticas del Este y un intento de reproducir Adocentyn, una alternativa cultural a la Europa escolástica.

Por su parte, Pico della Mirandola tenía un ejemplar del Picatrix en su biblioteca, y tuvo muy en cuenta el capítulo 6 del libro I, que constituye un auténtico elogio de la dignidad humana (Fauquier, 2000: 137).

Asimismo, el principio fundamental en el que se basan las técnicas presentadas en el Picatrix, a saber, que solo el examen astrológico del firmamento puede proporcionar al mago la indicación exacta del momento propicio para llevar a cabo sus operaciones, es el que siguieron, por ejemplo, Nostradamus y Cornelio Agrippa en su De occulta philosophia, algo completamente ajeno al espíritu y la letra de la obra de Tolomeo (Faracovi, 2014: 97).

En fin, un último detalle relacionado con nuestro tratado es que en Picatrix II, 2 se indicaba que existían dos tipos de figuras en el cielo, las constelaciones y las que usaban los hindúes: Et multo magis forme signorum zodiaci mutantur aliis quia in annis mille de facie ad faciem mutantur. [...] Secundus motus est figurarum celi estimatarum secundum opinionem Indorum. Pues bien, en el arte renacentista encontramos frescos de temática astrológica en los que se representaban precisamente los decanos de la astrología india. Es muy posible que esta curiosa temática artística se deba a la influencia de Abu Ma’shar, quien, en su Gran Introducción, en el capítulo relativo a los signos del zodíaco, resumía las distintas versiones de los decanos según los persas, los indios y los griegos (cf. Blume, 2014: 339). Pues bien, todo apunta a que no se trata de un simple motivo pictórico, sino que, de acuerdo con la magia astral, tan de moda al menos en el siglo XV entre autores como Ficino y otros, tales imágenes tendrían gran importancia por servir como una suerte de talismanes (Blume, 2014: 340). 
Sin embargo, esta amplia difusión y el hecho de que incluso hubiera versiones, completas o parciales, de la obra a lenguas como el inglés, el francés, el alemán, el italiano y el hebreo (Pingree, 1986: XV, n. 6), no debe llevarnos a engaño: el Picatrix fue para muchos autores renacentistas algo parecido a una obra «maldita». Así, no se hizo entonces una edición impresa del mismo, lo cual explica el gran número de copias manuscritas conservadas de la época, y son muchos los autores que se mostraron críticos con ella: Rabelais condena en Le Tiers Livre (1546) a un tal Picatris: «Le reverend père en diable Picatris, recteur de la faculté diabologique». Su contemporáneo, el pensador francés Symphorien Champier, criticaba el libro como inútil y lleno de supersticiones; en fin, el abad benedictino y ocultista Johannes Trithemius tampoco ahorró críticas contra el tratado (Attrell - Porreca, 2019: 6).

Fuera de las fuentes clásicas y medievales que dieron vida a la astrología renacentista, es el momento de centrarnos en dos obras que ejercieron una notable influencia en la manera de concebir y practicar el arte astrológico de entonces, el De vita coelitus comparanda de Ficino y el De revolutionibus de Copérnico.

El primero, De vita coelitus comparanda, 'Sobre la obtención de vida del cielo', es el tercer libro del De vita, de Marsilio Ficino, publicado en Florencia en 1489. En él el autor actúa como médico, dando una serie de orientaciones y recetas para tener una vida sana (De vita sana, libro I) y larga (De vita longa, libro II), complementadas con la posibilidad de beneficiarse de las influencias procedentes del cosmos, que es lo que recoge el libro III.

Este libro, basado todo él, como reconoce el autor, en el Liber de favore coelitus hauriendo de Plotino ${ }^{20}$, fue un intento de reconciliar las teorías de las distintas escuelas médicas, incluidos los remedios astrológicos y mágicos, con el neoplatonismo (Klibansky - Panofsky - Saxl, 2004: 257), sin olvidar que en la exposición de las teorías astrológicas demuestra un buen conocimiento de Tolomeo.

La teoría cosmológica, de origen platónico y neoplatónico, que sustenta los postulados de este libro es la creencia en un cosmos unificado, en el que el mundo terrenal y el celeste se ven sometidos a un constante intercambio de fuerzas. De este modo, todas las cosas y seres vivos se ven impregnados de las cualidades de los astros ${ }^{21}$.

En el caso del hombre, este se compone de corpus, anima y spiritus, este último un fluido sutilísimo que sirve de nexo entre los dos primeros, que es generado por la sangre, aunque actuaba solo en el cerebro. Esta triplicidad de componentes del ser humano tiene su perfecta correspondencia también con una división similar en el universo, compuesto por materia, mente universal y spiritus mundanus.

Los rayos que emiten los astros, que son el vehículo de su influencia, tocan directamente al spiritus mundanus, confiriéndole cualidades astrales. Este las traspasa

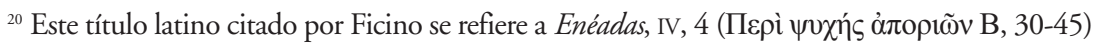

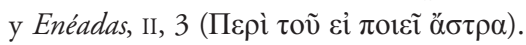

${ }^{21}$ Para toda esta exposición, cf. Klibansky - Panofsky - Saxl (2004: 258-260). 
al spiritus humanus, que, dado su papel de nexo entre el cuerpo y el alma, puede traspasarlos tanto a uno como a otro. Solo la parte física del hombre está realmente sometida a las influencias astrales, no así las facultades del alma, en particular la mens, que es esencialmente libre.

Dentro de este esquema es donde Ficino aplica los diversos remedios, que proceden de las prescripciones de los médicos árabes y salernitanos -fundamentalmente, de régimen de vida, como evitar la intemperancia, dividir razonablemente el día, vivienda y alimento adecuados, caminar y música-, medicamentos preparados con plantas, además de inhalaciones fragantes y, sobre todo, la magia talismánica, tal como hemos visto en el Picatrix, la más eficaz porque concentraba en el talismán toda la influencia de los astros (Klibansky - Panofsky - Saxl, 2004: 260-261).

Con sus doctrinas, Ficino no solo legitimó la magia astral en un contexto cristiano, sino que también elevó a los dioses planetarios «to a more important function by emphasizing their role as aspects of the internal, individual psyche with whom one can genuinely communicate» (Campion, 2009: 90).

La influencia que este libro ejerció sobre la medicina astral del Renacimiento fue determinante, en particular, en aspectos como la idea de que el magus, "can manipulate material objects in order to draw down the benefit of higher cosmic and inmaterial forces through which he is united with the World-Soul» (Hirai, 2014: 168). En concreto, el médico Jean Fernel (1497-1558) adoptó la teoría ficiniana del Espíritu del Mundo en su obra más importante, De abditis rerum causis, logrando así establecer una concordancia no solo entre Aristóteles y Platón, sino también entre los griegos y los cristianos (Hirai, 2014: 271). En fin, es de sobras conocida la gran influencia que esta obra ejerció en Giordano Bruno, algo que llevó a algunos contemporáneos a acusarle de plagio (Garin, 1981: 148, n. 33).

Respecto a Copérnico, independientemente de la apuesta por el heliocentrismo de su autor ${ }^{22}$, los cálculos matemáticos contenidos en su libro demostraron ser más exactos que los de las Tablas alfonsinas, lo que con el tiempo provocó su desprestigio y su sustitución por otras más exactas, confeccionadas a partir de los cálculos hechos por Copérnico, como las Tablas pruténicas (Tabulae prutenicae) o prusianas, elaboradas por el astrónomo alemán Erasmo Reinhold y publicadas en 1551 bajo el patrocinio de Alberto I, duque de Prusia. Reinhold, que era enemigo del heliocentrismo, partió para la constitución de sus tablas de la posición de Saturno en el nacimiento del duque (17 de mayo de 1490) ${ }^{23}$.

Un año antes, Rheticus, el discípulo de Copérnico, había elaborado unas efemérides siguiendo las doctrinas de su maestro: Ephemeris ex fundamentis Copernici, Leipzig, 1550.

${ }^{22}$ En realidad, el centro del cosmos copernicano no era el sol, sino el centro de la órbita de la tierra. Solo con la Astronomia nova de Kepler el sol físico fue considerado el verdadero centro del universo (Campion, 2009: 108).

${ }^{23}$ Sobre estas tablas y su autor, cf. Gingerich (1973). 
Por su parte, Peucer, que era profesor de la Universidad de Wittenberg, expuso, en sus Elementa doctrinae de circulis coelestibus et primo motu (1551), que, aunque había que rechazar el heliocentrismo, había que autorizar los métodos matemáticos contenidos en el De revolutionibus (Vernet, 2000: 157-158).

En fin, Tycho Brahe y Johannes Kepler, que mejoraron ciertos aspectos del sistema copernicano -Brahe, que creó el sistema ticoniano, que suponía una síntesis entre el geocentrismo de Tolomeo y el heliocentrismo de Copérnico, y Kepler, quien en sus Harmonices mundi (1618) estableció sus conocidas tres leyes del movimiento de los planetas-, basándose en las muy precisas observaciones astronómicas del primero, compilaron las Tablas rudolfinas (Tabulae Rudolphinae), así llamadas por el emperador alemán Rodolfo II, bajo cuyo patrocinio habían trabajado. Dichas tablas, publicadas en 1627 por Kepler, contenían las posiciones de 1005 estrellas, muchas más que las localizadas por Tolomeo, así como instrucciones y tablas para localizar los planetas del sistema solar. Eran tan precisas que fueron las utilizadas por astrónomos y astrólogos a lo largo de todo el siglo XVII (Gingerich, 1971).

Por tanto, podemos decir que fue la exactitud de sus cálculos matemáticos lo que explica que la publicación del De revolutionibus fuera tan esperada, «the hope being that it would end the astronomical errors and uncertainties that aflicted astrology» (Campion, 2009: 109).

A modo de conclusión, el análisis de las fuentes de la astrología renacentista nos ha revelado un panorama muy complejo y diverso. Por un lado, existe una fuerte corriente conservadora, que se extiende sobre todo a lo largo del siglo XV, continuista con las técnicas y las doctrinas medievales, la mayoría de inspiración árabe, que conoce a Tolomeo en las versiones latinas medievales y que reaccionó de inmediato a las críticas de que fue objeto por parte de Pico, mostrándose aparentemente inmune a las mismas, de la que serían representantes Domenico Maria da Novara y el propio Giovanni Pontano.

Frente a esta existe una corriente reformista, que se inicia a finales del XV y sobre todo a comienzos del XVI, que comparte muchas de las críticas expuestas en las Disputationes de Pico, que las hace suyas y que le llevan a intentar una refundación del arte astrológico a partir de la recuperación de Tolomeo, del Tetrabiblos, pero también del Centiloquium -amén de otros grandes astrólogos antiguos-, mediante nuevas ediciones, traducciones y comentarios, con el objetivo de liberarlo de todas las nugae Arabum, responsables del descrédito de la astrología por su apuesta por la adivinación y la superchería. A pesar de todo, tan laudable objetivo no se pudo alcanzar por las propias limitaciones de las doctrinas tolemaicas, como en el caso de la teoría de las grandes conjunciones, de origen árabe, aceptada incluso por los mejores comentaristas de Tolomeo para la predicción de sucesos pertenecientes a la apotelesmática universal. Asimismo, en este esfuerzo por recuperar a los clásicos se inscriben dos importantes descubrimientos: que el Centiloquium no era obra del maestro alejandrino, por Cardano, y que el Corpus Hermeticum tenía un componente griego más importante del que se creía entonces, obra de Casaubon. Y, quizás lo más interesante, los grandes descubrimientos astronómicos que se produjeron en el XVI y en el XVII, en particular los que llevaron a cabo Copérnico y algunos de sus seguidores, fueron 
protagonizados por reformistas de la astrología, convencidos de que una mejora en los cálculos matemáticos y en el conocimiento de la mecánica celeste eran fundamentales para mejorar los pronósticos astrológicos, cada vez más alejados de la mera adivinación.

Por último, como hemos visto también, la recuperación de los textos herméticos, y su difusión gracias a las traducciones de Marsilio Ficino, fue fundamental no solo para la astrología o la práctica de la magia natural, a menudo basada en la elaboración de talismanes, dado que el hermetismo permeó muchos ámbitos del mundo de entonces, entre ellos, la filosofía, la religión y la cultura. Y de nuevo aquí fue básica la contribución de un texto medieval, de origen árabe y traducido al latín, el Picatrix, sin olvidar el De vita coelitus comparanda de Ficino, que tanta huella dejó en los hermetistas y en los practicantes de la medicina astral.

\section{BIBLIOGRAFÍA CITADA}

AKopyan, O. (2017): «Princeps aliorum and his followers: Giovanni Pico della Mirandola on the 'Astrological Tradition' in the Disputationes adversus astrologiam divinatricems, Renaissance Studies 32: 4.

Atrell, D. - Porreca, D. (2019): Picatrix: A Medieval Treatise on Astral Magic. Magic in History, Pennsylvania State University Press, University Park (Pennsylvania).

Ben-Zaken, A. (2020): «Traveling with the Picatrix: cultural liminalities of science and magic», en M. FuCHS et al. (eds.), Religious Individualisation, De Gruyter, Berlin-Boston, pp. 1033-1064.

BeZZA, G. (2014): «Representation of the Skies and the Astrological Chart», en Br. Dooley (ed.), A Companion to Astrology in the Renaissance, Brill, Leiden-Boston, pp. 59-98.

Blume, D. (2014): «Picturing the Stars: Astrological Imagery in the Latin West, 1100-1550», en Br. Dooley (ed.), A Companion to Astrology in the Renaissance, Brill, Leiden-Boston, pp. 333-398.

Bònoli, F. - Bezza, G. - De Meis, S. - Colavita, C. (2012): I pronostici di Domenico Maria da Novara, Leo S. Olschki, Firenze.

Campanella, T. (1629): Astrologicorum libri VI, Leyden.

CAmpIon, N. (2009): A History of Western Astrology, vol. II. The Medieval and Modern Worlds, Continuum, London-New York.

Compagni, V. P. (1977): «La magia cerimoniale del 'Picatrix' nel Rinascimento», Atti dell'Accademia di Scienze Morali e Politiche 88: 279-330.

Dooley, Br. (ed.) (2014): A Companion to Astrology in the Renaissance, Brill, Leiden-Boston.

Dooley, Br. (2014): «Introduction», en Br. DoOley (ed.), A Companion to Astrology in the Renaissance, Brill, Leiden-Boston, pp. 1-15.

EAMON, W. (2014): «Astrology and Society», en Br. DOOLEY (ed.), A Companion to Astrology in the Renaissance, Brill, Leiden-Boston, pp. 141-191.

Faracovi, O. (2014): «The Return to Ptolemy», en Br. Dooley (ed.), A Companion to Astrology in the Renaissance, Brill, Leiden-Boston, pp. 87-98.

FAUQUIER, Fr. (2000): «Le magicien-philosophe dans le Picatrix latin», en A. MOREAU - J.-C. TURPIN (eds.), La magie. Vol. 3. Du monde latin au monde contemporain, Université Paul Valéry, Séminaire d'Étude des Mentalités Antiques, Montpellier, pp. 129-146. 
FERABOLI, S. (2010): Claudio Tolomeo. Le previsioni astrologiche (Tetrabiblos), Fondazione Lorenzo Valla Arnoldo Mondadori Editore, Milano [6a ed.].

Ferrer Ventosa, R. (2019): «La filosofía de Hermes. Investigación sobre el estudio del hermetismo como fenómeno histórico y su estado actual», Comprendre 21 (1): 5-26.

Festugière, A.-J. (1967): Hermétisme et mystique païenne, Aubier, Paris.

GARIN, E. (1981): El zodíaco de la vida. La polémica astrológica del Trescientos al Quinientos, Península, Barcelona.

Gingerich, O. (1971): «Johannes Kepler and the Rudolphine Tables», Sky \& Telescope 42 (Dec.): 328-333.

Gingerich, O. (1973): «The role of Erasmus Reinhold and the Prutenic Tables in the dissemination of Copernican Theory», Studia Copernicana 6: 43-62.

Hirai, H. (2014): «The New Astral Medicine», en Br. Dooley (ed.), A Companion to Astrology in the Renaissance, Brill, Leiden-Boston, pp. 267-286.

HOfMeier, T. (2002): «Cudworth versus Casaubon: historical versus textual criticism», en C. GiLLY - C. van HeEertum (eds.), Magic, Alchemy and Science 15th-18th centuries. The influence of Hermes Trismegistus, vol. I, Centro Di Edizioni, Florencia-Venecia-Amsterdam, pp. 581-586.

HÜBNER, W. (1980): «Die Rezeption des astrologischen Lehrgedichts des Manilius in der italienischen Renaissance», en R. SchmitZ - Fr. KrafT (eds.), Harald Boldt, Boppard, pp. 39-67.

HÜBNER, W. (2014): «The Culture of Astrology from Ancient to Renaissance», en Br. Dooley (ed.), A Companion to Astrology in the Renaissance, Brill, Leiden-Boston, pp. 17-58.

KIngsley, P. (2000): «Poimandres: The Etymology of the Name and the Origins of the Hermetica», en R. van Den Broek - C. van Heertum (eds.), From Poimandres to Jacob Böhme: Gnosis, Hermetism and the Christian Tradition, Bibliotheca Philosophica Hermetica, In de Pelikaan, Amsterdam, pp. 41-76.

KlibAnSky, R., PANOFSKY, E. - SAXL, Fr. (2004): Saturno y la melancolía. Estudios de historia de la filosofia de la naturaleza, la religión y el arte, Alianza Editorial, Madrid [1 ${ }^{a}$ reimpr.].

LeHrich, Ch. I. (2007): The Occult Mind: Magic in Theory and Practice, Ithaca, Cornell University Press.

PINGREE, D. (1986): Picatrix, the Latin Version of the Ghayat al-hakim, Studies of the Warburg Institute, London, 1986.

Monat, P. (2002): Firmicus Maternus. Mathesis, Livres I-II, Les Belles Lettres, Paris.

Renau Nebot, X. (1999): Textos Herméticos, BCG, Gredos, Madrid.

RINALDI, M. (2002): «Sic itur ad astra». Giovanni Pontano e la sua opera astrologica nel quadro della tradizione manoscritta della «Mathesis» di Giulio Firmico Materno, Studi Latini, 45, Napoli.

Vernet, J. (2000): Astrología y astronomía en el Renacimiento, El Acantilado, Barcelona [ed. anterior, Ariel, 1974].

Vescovini, Gr. F. (2014): «The Theological Debate», en Br. Dooley (ed.), A Companion to Astrology in the Renaissance, Brill, Leiden-Boston, pp. 99-140.

YATES, Fr. A. (1982): La filosofía oculta en la época isabelina, FCE, México.

YATES, Fr. A. (1983): Giordano Bruno y la Tradición Hermética, Ariel, Barcelona [2ºd.].

Zambelli, P. (2007): White Magic, Black Magic in the European Renaissance: From Ficino, Pico, Della Porta to Trithemius, Agrippa, Bruno, Brill, Leiden. 
